\title{
Diagnosis at a first glance? "Bulging eyes" as a clue for a more accurate diagnosis in spinocerebellar ataxias
}

\author{
Diagnóstico à primeira vista? Retração palpebral como uma pista para um diagnóstico \\ mais preciso nas ataxias espinocerebelares
}

José Luiz Pedroso

\author{
MD, PhD; Department of Neurology, \\ Ataxia Unit, Universidade Federal \\ de São Paulo (UNIFESP), São Paulo \\ SP, Brazil. \\ Correspondence \\ José Luiz Pedroso \\ Avenida Onze de Junho 582 / apto. 131 \\ 04041-002 São Paulo SP - Brasil \\ E-mail:jlpedroso.neuro@gmail.com \\ Conflict of interest \\ There is no conflict of interest to \\ declare. \\ Received 30 April 2013 \\ Received in final form 02 May 2013 \\ Accepted 09 May 2013
}

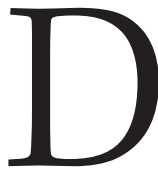
espite so many genetic discoveries, ease for a genetic test and even exome sequencing, it is almost impossible to conduct a diagnostic approach for hereditary neurological diseases without semiotic observations. The contemplative method of Osler and clinical observation of Charcot are lessons left for our generation, which are crucial elements for clinical diagnosis ${ }^{1}$. In line with these comments, "bulging eyes" or Collier's sign, in the context of an autosomal dominant spinocerebellar ataxia (SCA), is a marked diagnostic clue and should promptly guide our genetic investigation for spinocerebellar ataxia type 3 (SCA3) or Machado-Joseph disease (MJD).

"Bulging eyes" indicates widening of the palpebral opening with white parts of the sclera appearing above and, often, below the limbus. It was previous indicated with different and controversial eponyms including Graefes, pseudo-Graefe's, Stellwag's or Dalrymple's sign, which were originally assigned to endocrinological conditions ${ }^{2}$. James Collier described eyelid retraction in neurological diseases related to lesions of posterior commissure and also some neurodegenerative diseases in 1927, and he called this finding "tucked lids" 3 . Subsequently, in honor to the first description of eyelid retraction, it was named Collier's sign. This sign, also known as "bulging eyes", is usually related to midbrain lesions, particularly in the rostral midbrain and posterior commisure, and is usually caused by infarction, tumor, multiple sclerosis or encephalitis ${ }^{2}$. Moreover, "bulging eyes" may be sporadically found in neurodegenerative disorders, such as Parkinson's disease, progressive supranuclear palsy, dementia with Lewy bodies, and most frequently in SCA3.

The article by Moro et al. ${ }^{4}$ publish in this issue of Arquivos de Neuro-Psiquiatria brings back the relevance of semiotic features in genetic diseases. Currently, there are over 30 subtypes of SCA, and it is impossible to test all subtypes at the same time. Neurologists in daily clinical practice need a clue, a mark, a sign, in order to request a specific genetic test when evaluating a patient with SCA. They need to have a broad knowledge of the genotype-phenotype relationship. Thus, subtle changes in neurological examination, as the presence of "bulging eyes", can guide genetic testing for a specific SCA subtype. In this article, Moro et al. found "bulging eyes" in $65.2 \%$ of all SCA3 patients, and only in $4.7 \%$ in other SCA. Although it may seem an overstatement, in the context of an unknown SCA, boldest neurologists could say that "we recognize a SCA3 patient when he comes in through the door", by looking at the patient's face and observing "bulging eyes".

SCA3 is the most common SCA worldwide, and this is not different in Brazil ${ }^{5}$. SCA represents an extensive and complex group of autosomal dominant neurodegenerative diseases, and to date, SCA1, SCA2, SCA3, SCA6 and SCA7 are the most frequently identified subtypes. SCA have a wide range of neurological symptoms including axial and appendicular ataxia, dysarthria, oculomotor disturbances, extrapyramidal signs and several non-motor clinical manifestations. Anatomical, physiological, clinical and functional neuroimaging data reinforce the idea of a degenerative process involving extra-cerebellar regions in $\mathrm{SCA}^{6}$. The presence of "bulging eyes" plays a crucial role on pathological issues 
involving SCA, and usually indicates structural damage or degenerative process in the midbrain?

Interestingly, ocular abnormalities may differ between SCA subtypes. Ophthalmoplegia is more pronounced in SCA2 and SCA7, but is also observed in a lesser extent in SCA1 and SCA3. Nystagmus is a very common sign in almost all SCA subtypes, while visual loss is restricted to SCA7. As for "bulging eyes", there are few studies evaluating its frequency between SCA subtypes. Although "bulging eyes" is a very frequent ocular abnormality in SCA3 patients, it may be rarely found in other $\mathrm{SCA}^{8,9}$.

Considering the findings published by Moro et al., majority of patients with SCA3 present "bulging eyes", in opposite to other SCA. Therefore, this ocular abnormality might be used as guide for the differential diagnosis of SCA and a more accurate indication of a genetic testing.

\section{References}

1. Pedroso JL, Barsottini OG. Neurological contributions from William Osler. Arq Neuropsiquiatr 2013;71:258-260.

2. Onofrj M, Monaco D, Bonanni L, et al. Eyelid retraction in dementia with Lewy bodies and Parkinson's disease. J Neurol 2011; 258:1542-1544

3. Collier J. Nuclear ophthalmoplegia, with special reference to retraction of lids and ptosis and to lesions of posterior commissure. Brain 1927;50:488-498.

4. Moro A, Munhoz RP, Arruda WO, Raskin S, Teive HAG. Clinical relevance of "bulging eyes" for the differential diagnosis of spinocerebellar ataxia. Arq Neuropsiquiatr 2013;71:428-430.

5. Pedroso JL, Braga-Neto P, Radvany J, Barsottini OG. MachadoJoseph disease in Brazil: from the first descriptions to the emergence as the most common spinocerebellar ataxia. Arq Neuropsiquiatr 2012;70:630-632.

6. Pedroso JL, Felicio AC, Braga-Neto P, Barsottini OG. Movement disorders in spinocerebellar ataxias. Mov Disord 2011;26:2302.

7. Schmidtke K, Büttner-Ennever JA. Nervous control of eyelid function A review of clinical, experimental and pathological data. Brain 1992;115:227-247.

8. Teive HA, Munhoz RP, Arruda WO, et al. Spinocerebellar ataxias: genotype-phenotype correlations in 104 Brazilian families. Clinics (São Paulo) 2012;67:443-449

9. Jardim LB, Pereira ML, Silveira I, Ferro A, Sequeiros J, Giugliani R. Neurologic findings in Machado-Joseph disease: relation with disease duration, subtypes, and (CAG). Arch Neurol 2001;58:899-904. 